\title{
Review
}

\section{The biological significance of kinesin-mediated intracellular transport: insights from the $C$. elegans research}

\author{
Li Wang ${ }^{1 \#}$, Fengyun Duan ${ }^{2 \#}$, He Liu ${ }^{2 *}$, Taihong Wu ${ }^{2 *}$, Wenxing Yang ${ }^{2,3 *}$ \\ ${ }^{1}$ Department of Physiology, Johns Hopkins University, Baltimore, MD, USA; ${ }^{2}$ Department of Organismic and \\ Evolutionary Biology, Center for Brain Science, Harvard University, Cambridge, MA, USA; ${ }^{3}$ Department of \\ Physiology, West China School of Basic Medical Sciences and Forensic Medicine, Sichuan University, Chengdu, \\ Sichuan, China
}

\#Li Wang and Fengyun Duan contributed equally to this work.

*Address for correspondence: Dr. Wenxing Yang, Ph. D., Department of Organismic and Evolutionary Biology, Center for Brain Science, Harvard University, Cambridge, MA 02138, USA. Email: wenxingyang @ fas.harvard.edu Co-correspondence author: Dr. He Liu, Ph. D., Department of Organismic and Evolutionary Biology, Center for Brain Science, Harvard University, Cambridge, MA 02138, USA. Email: heliu @ fas.harvard.edu

Co-correspondence author: Dr. Taihong Wu, Ph. D., Department of Organismic and Evolutionary Biology, Center for Brain Science, Harvard University, Cambridge, MA 02138, USA. Email: taihongwu@ fas.harvard.edu

Received February 28, 2019; Accepted March 17, 2019

\begin{abstract}
As one of the major performers for intracellular transport, kinesins are widely involving in many intracellular processes by delivering the intracellular cargos along the microtubules to their destination. Thus, kinesins play critical roles in maintaining proper cell morphology and functions. As one of the eukaryotic model animals, C. elegans shares lots of conserved biological pathways with mammals. Up to now, about 20 kinesin-like proteins (KLP) are found in $C$. elegans. In this review, we focus on the recent ten years' findings on kinesin-mediated intracellular transport in $C$. elegans research. These findings either revealed new mechanisms underlying conserved physiological processes among species, or may inspire the researchers for understanding human biology.
\end{abstract}

Key Words: C. elegans, kinesin, intracellular transport

Each cell in our body runs like a small world. It has the cellular factories to generate cellular materials, such as ribosomes for generating proteins. Molecular motors function as cellular level vehicles to locate these intracellular materials to their destination. Kinesin and dynein are the two major microtubule (MT)-associated molecular motors, they transport the molecular cargos along the MTs in different directions. Kinesin is responsible for delivering the cellular cargos toward the plus-end of the MT, which usually means to move the cargos from the cell body to the peripheral area of the cell. ${ }^{1}$ While dynein works oppositely to kinesin. The collaboration between kinesin and dynein keeps the intracellular transport in a dynamic hemostasis, which precisely controls the cell morphology and functions. As a eukaryote, C. elegans can serve as an ideally simplified model system for investigating the conserved biological pathways among species, including mammals. In recently years, the researchers from C. elegans research society made great progresses in understanding the biological significance of kinesins. We will summarize these findings in the following sections, and mainly focus on those related to human physiology and diseases.
Kinesin superfamily proteins

Kinesin superfamily proteins, usually refer as KIFs or kinesin, represent a class of motor proteins, which widely involve in intracellular transport of proteins, organelles, and RNA granules, etc. ${ }^{1}$ In 1985, Hirokawa et al. observed an extensive network that interconnect the MTs with the organelles by quick-freeze, deep-etch electron microscopy. ${ }^{2}$ This is possibly the first visual evidence for intracellular transport machinery. Later in this year,

This is an open access journal, and articles are distributed under the terms of the Creative Commons Attribution-NonCommercial-ShareAlike 4.0 License, which allows others to remix, tweak, and build upon the work non-commercially, as long as appropriate credit is given and the new creations are licensed under the identical terms.

For reprints contact: weda-h@weda-h.org

How to cite this article: Wang L, Duan FY, Liu H, Wu TH, Yang WX. The biological significance of kinesin-mediated intracellular transport: insights from the C. elegans research. J ADV HEALTH 2019; 1(2): 132-138. 
Vale et al. identified and named kinesin. ${ }^{3}$ Up to now, more than 40 kinesins were identified in human. ${ }^{1}$ Kinesin protein contains a molecular cargo binding domain and a conserved globular motor domain. The cargo binding domain, alone or together with adaptor proteins and/or scaffold proteins, forms specific molecular structure, which recognizes diverse molecular cargos (Figure 1). The motor domain usually possesses ATPase activity, which provides the energy for moving the kinesin and its cargos along the MTs. Generally, all the kinesins can be divided into 3 classes according to the location of their motor domains inside the proteins, namely $\mathrm{NH}_{2}$-terminal, middle or $\mathrm{COOH}$-terminal region. ${ }^{1}$ Alternatively, they can be divided into 2 classes according to their functions, namely conventional and unconventional kinesin. Conventional kinesins are those able to transport the cargo, such as KIF1A. ${ }^{4}$ Unconventional kinesin usually refers to those without ATPase activity, such as KIF2A and KIF26A. ${ }^{5,6}$ Lots of mammalian studies have revealed that dysfunction in kinesin related to Alzheimer disease, Huntington's disease, diabetes, polycystic kidney, megacolon, cancer, Charcot-Marie-Tooth disease, etc. ${ }^{6-13}$

C. elegans has a simplified anatomy, and has been used as a model animal for decades. C. elegans has many advantages for being a model animal, such as a stable and fully identified neuronal connectome, numerous mutants and genetic databases, easy to handle, short lifespan and economic culture conditions, etc. The researchers worldwide use C. elegans for different research topics, such as neuroscience, lifespan, cell cycle, cell division, etc. ${ }^{14-20} \mathrm{Up}$ to now, 20 kinesin-like proteins, 1 kinesin heavy chain protein and 2 kinesin light chain proteins have been identified in C. elegans, and they all have human orthologs and widely involve in diverse cellular/molecular functions (Table 1).
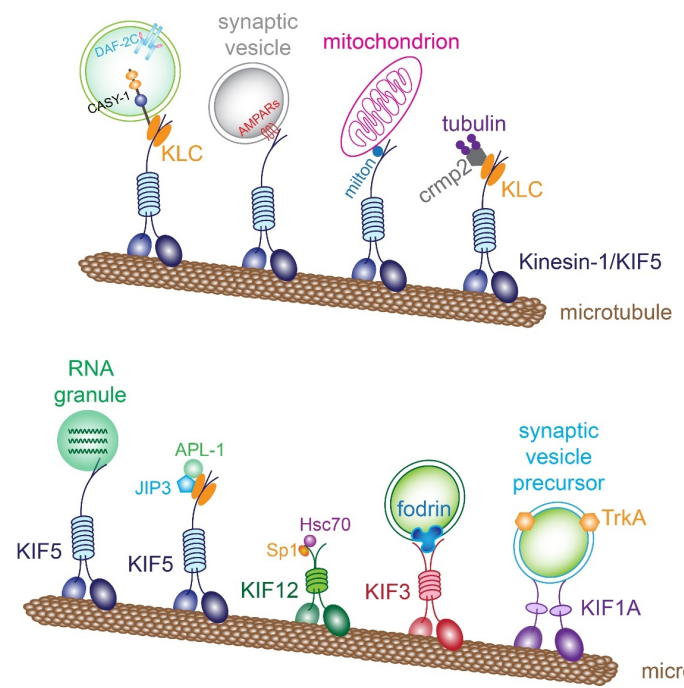

microtubule

Figure 1. Kinesins recognize different molecular cargos.

Kinesin-1 binds to different cargos through the binding structures which are formed by kinesin alone or together with adaptor/scaffold proteins. Kinesin-1/KIF5 transports 1) insulin peptide receptor DAF-2C by recognizing CASY-1 on the CASY-1/DAF-2C-containing vesicles, 2) AMPARs through synaptic vesicle, 3) mitochondrion by the help of its adaptor protein milton, 4) tubulin by binding complex formed togetherwith KLC and crmp2, 5) RNA granules, and 6) amyloid precursor protein homolog APL-1 by binding complex formed together with KLC and JIP3. KIF12 transports Sp1 by the help of chaperon protein Hsc70. KIF3 transports fodrin-associating vesicles. KIF1A transports TrkA-containing synaptic vesicle precursor. ${ }^{9,21-28}$

\section{Kinesin and axon/dendritic transport}

Comparing to other cells, neurons have diverse cell morphology and distinct functions. ${ }^{1}$ Synaptic machinery is tightly regulated by neuronal intracellular transportation, such as axon transport and dendritic transport. Proteins or signal peptides are synthesized and packed into synaptic vesicle precursors (SVP) or other intracellular membranous granules in the cell body, and then delivered to axons or dendrites. One of the major transporters for neuronal intracellular transportation in C. elegans is UNC-104, an ortholog of human KIF1A. Considering the complexity of the cargos, UNC-104/KIF1A generally involves in many biological processes in the neurons. Maeder et al. revealed that SVPs move bi-directionally throughout the entire neuron, including dendrites and distal axonal domains devoid of presynaptic sites, and UNC-104/KIF1A controls SVP trafficking in both axon and dendrites, which possibly rely on KIF1A's dimer formation. ${ }^{30,52}$ These observations imply that switching of the motor protein may be not necessary for SVP transition from one neuronal domain to another in the neurons. This economical and versatile mechanism may facilitate SVP trafficking throughout the entire neuron. ${ }^{30}$ Their data also propose the directionality of movement and generation of SVPs into the axon as important determinants for accurate presynaptic localization. ${ }^{30}$ Precise regulation of UNC-104/KIF1A-mediated axonal transport contributes to rapid assembly of presynaptic materials behind the growth cone in dopaminergic neurons. ${ }^{53}$ Synapse alterations, such as age-related synaptic decline, are the causes of neuronal dysfunctions in normal aging and in early stages of neurodegenerative diseases. ${ }^{54}$ Aging neurons exhibit decreased activity of UNC-104/KIF1A, which leads to the synaptic and behavioral decline in aged worms, suggesting the importance of axonal transport in the maintenance of synaptic structural integrity and function during aging. ${ }^{54}$ The autophagy-related protein ATG-9 is transported to presynaptic sites by UNC-104/KIF1A, and activates autophagy pathway contributing to presynaptic assembly in vivo. ${ }^{55}$ The C. elegans ortholog of mammalian calsyntenins, CASY-1, is required to modulate the transport of GABAergic SVPs through a possible interaction with UNC-104/KIF1A. ${ }^{56}$

UNC-116 is an ortholog of human Kinesin-1, or referred as conventional kinesin or KIF5. UNC-116/ Kinesin-1 is a heterotetramer, which is composed of two catalytic kinesin heavy chain (KHC) and two accessory kinesin light chain (KLC). In a recent study, Hoerndli et al. found that UNC-116/Kinesin-1 binds to and transports AMPA-type glutamate receptors (AMPARs, Figure 1), and thus modifies synaptic strength by controlling cargo delivery, removal, and redistribution. They also found that UNC-116/Kinesin-1-mediated proper distribution of heteromeric GLR-1/GLR-2 AMPARs, not that of homomeric GLR-1 AMPARs, is important for proper glutamate-gated currents. ${ }^{22}$ They later discovered that CaMKII plays a critical role in synaptic plasticity by regulating AMPARs transport, and UNC-116/Kinesin-1 subunit KLC is the target of CaMKII in this process. ${ }^{57}$ In addition, the KLP-4, an ortholog of human Kinesin-3, regulates anterograde trafficking of GLR-1 glutamate receptors in the ventral nerve cord of C. elegans. ${ }^{34}$ UNC-116/Kinesin-1 subunit KLC binds to the intracellular C-terminal domain of calsyntenin/CASY-1, which interacts with insulin receptor DAF-2C in intracellular membranous granules in ASER axon (Figure 1). The CASY-1 and kinesin-1 complex thus confers functional specificity to the insulin receptor through rapid translocation of these granules to the 
synaptic region. ${ }^{21}$ Considering both insulin signaling and calsyntenins play important roles in memory performance and Alzheimer's disease in humans, these findings may lead to further understanding of the mechanisms underlying human memory formation and dementia. ${ }^{21}$ Synaptic vesicle transportation relies on both kinesin and dynein. ${ }^{58}$ Kinesin is responsible for anterograde axonal transport, while dynein is for retrograde axonal transport.
Dynein is synthesized in the cell body, and transporting cargos from peripheral region to cell body, implying a mechanism distributing dynein from cell body to the axon peripheral region. Arimoto et al. showed that kinesin-1 transports dynein by the help of its adaptor protein UNC-16/JIP3. ${ }^{26}$ This tertiary complex is then responsible for retrograde transport of the amyloid precursor protein homolog APL-1. ${ }^{26}$

Table 1. Kinesins in C. elegans and their human orthologs and binding partners. Human orthologs are suggested by WormBase (http://wormbase.org). "/" denotes "not applicable" or "not characterized".

\begin{tabular}{|c|c|c|c|}
\hline \multicolumn{2}{|c|}{ Name } & \multirow{2}{*}{ Human ortholog(s) } & \multirow{2}{*}{ Binding partner(s) } \\
\hline Kinesin-related & Alternative & & \\
\hline KLP-1 ${ }^{29}$ & UNC-104 & KIF1A/1B/1C & $\mathrm{SVP}^{30}$ \\
\hline KLP-2 ${ }^{31}$ & OSM-3 & KIF17 & IFT-particle A/B ${ }^{32}$ \\
\hline KLP-3 ${ }^{33}$ & I & $\mathrm{KIFC} 1 / \mathrm{C} 2 / \mathrm{C} 3$ & I \\
\hline KLP-4 $4^{34}$ & I & KIF13A/13B & AMPARs ${ }^{34}$ \\
\hline KLP- $5^{35}$ & VAB-8 & $\mathrm{KIF} 21 \mathrm{~A} / 21 \mathrm{~B} / 26 \mathrm{~A}$ & I \\
\hline KLP- $6^{36}$ & I & KIF1B & $\mathrm{KBP}$, mitochondrion ${ }^{37}$ \\
\hline KLP-7 ${ }^{38}$ & l & $\mathrm{KIF} 2 \mathrm{~A} / 2 \mathrm{~B} / 2 \mathrm{C}$ & I \\
\hline KLP-8 ${ }^{35}$ & GCC-1 & $\mathrm{GCC} 1$ & I \\
\hline KLP-9 ${ }^{39}$ & ZEN-4 & KIF23 & $\mathrm{CYK} 4{ }^{40}$ \\
\hline KLP-10 ${ }^{35}$ & l & KIF15 & l \\
\hline KLP-11 ${ }^{41}$ & I & $\mathrm{KIF} 3 \mathrm{~B} / 3 \mathrm{C}$ & IFT-particle $\mathrm{A}^{32}$ \\
\hline KLP-12 ${ }^{42}$ & l & KIF21A/21B & l \\
\hline KLP-13 ${ }^{35}$ & I & KIF19 & l \\
\hline KLP-14 ${ }^{35}$ & BMK-1 & KIF11 & I \\
\hline KLP-15 ${ }^{43}$ & l & $\mathrm{KIF} 12 / \mathrm{C} 1 / \mathrm{C} 3$ & l \\
\hline KLP-16 ${ }^{44}$ & I & $\mathrm{KIF} 12 / \mathrm{C} 1 / \mathrm{C} 3$ & I \\
\hline KLP- $17^{45}$ & I & $\mathrm{KIF} 4 \mathrm{~A} / \mathrm{C} 1 / \mathrm{C} 3$ & I \\
\hline KLP-18 ${ }^{46}$ & I & KIF15 & MESP-1 ${ }^{47}$ \\
\hline KLP-19 ${ }^{42}$ & I & $\mathrm{KIF} 4 \mathrm{~A} / 4 \mathrm{~B}$ & $\mathrm{SUMO}^{48}$ \\
\hline KLP- $20^{35}$ & I & KIF3A & IFT-particle A ${ }^{49}$ \\
\hline KHC- $1^{50}$ & UNC-116 & KIF5A/5B/5C & AMPARs ${ }^{22}$ \\
\hline KLC- $1 / 2^{51}$ & 1 & $\mathrm{KLC} 1 / 2 / 3 / 4$ & CASY- $1^{21}$, JIP3 $^{26}$ \\
\hline
\end{tabular}

\section{Kinesin and circuit remodeling}

Synapse density and connectivity changes actively during different phases of animal development. Once circuit remodeling/rewiring starts, synapse assembly and disassembly happens simultaneously. Park et al. reported that the sequential actions of anterograde and retrograde motors UNC-104/KIF1A and dynein lead the patterning of new pre-synaptic terminals, while the synapse elimination from the DD neuron ventral neurite is mediated in part by the cyclin Y homolog CYY-1 and the apoptotic cell death pathway. ${ }^{59,60}$ Besides, dynamic MTs are required for UNC-116/ Kinesin-1-mediated SV vesicle transport to DD neuron dorsal neurite during circuit remodeling. ${ }^{61}$

\section{Kinesin and cell migration}

Neurons migrate to the proper position during the development of the nervous system, this process is partly under the control of the UNC-116/Kinesin-1 in PHB sensory neurons. Barsi-Rhyne et al. revealed that UNC-116/Kinesin-1 acts in part with the cell and axon migration molecules UNC-6/Netrin and UNC-40/DCC in this process, which suggests an active posterior cell migration mediated by UNC-116/Kinesin-1 occurs throughout development to maintain proper PHB cell body position, and defines a new pathway that mediates maintenance of neuronal cell body position. ${ }^{62}$

\section{Kinesin and cytoskeleton}

Kinesin-13 is an unconventional kinesin, which uses the energy from ATP hydrolysis for depolymerizing the MTs. ${ }^{63} \mathrm{KLP}-7$, an ortholog of human Kinesin-13, helps to restrict the growth of MTs in the steady state in mature axons. KLP-7 is downregulated locally, and the number of growing MTs increases at the injury site of the injured axon, suggesting certain contributions of KLP-7 downregulation in axon regeneration. ${ }^{38} \mathrm{KLP}-7$ is a mitotic centromereassociated kinesin, KLP-7 deletion mutant showed ectopic MT growth, which affects the functions of both mitotic and meiotic spindle. ${ }^{64}$ KLP-7 is mostly phosphorylated in vivo by aurora kinase, and the conserved aurora phosphorylation site S546 is essential for KLP-7-mediated depolymerization of the MTs. ${ }^{64}$ These findings together propose a regulatory mechanism of KLP-7's MTdepolymerizing function by aurora kinase-mediated phosphorylation. The microtubule depolymerase activity of KLP-7 benefits the cells, such as oocytes, by preventing ectopic, 
spontaneous microtubule assembly when centrosome activity is defective or absent, which would otherwise lead to spindle microtubule disorganization and aneuploidy. ${ }^{65}$

Defect in Kinesin-1 contributes to axon degeneration due to mitochondria misdistribution and lost. In the wild-type C. elegans, mitochondria are distributed along the entire axon. However, in UNC-116/Kinesin-1 mutants, mitochondria are located almost exclusively in the cell bodies. ${ }^{66}$ In the GABAergic motor neuron of the UNC-116/Kinesin-1 mutants, laser axotomy causes a severe loss of mitochondria in their injured axons, which leads to a massive degeneration of these axons. This may due to their severe health impairments or to a general disruption in axon transport. However, mutants for UNC-104/KIF1A, which are equally unhealthy and deficient for key axon components, such as synaptic vesicles, ${ }^{67}$ have wild-type levels of degeneration. These findings collectively propose UNC-116/Kinesin-1-mediated proper distribution of mitochondria as a protecting mechanism which keeps axons from degeneration. ${ }^{66}$

UNC-116/Kinesin-1 is also a major regulator for neuronal cytoskeleton. ${ }^{68-70}$ UNC-116/Kinesin-1 defines the minus-end-out MT organization of the dendrite in vivo. In UNC-116/Kinesin-1 mutants, the dendritic MTs adopt an axonal-like plus-end-out organization. UNC-116/Kinesin-1 is able to cross-link antiparalleled MTs in vitro. All these findings propose that kinesin-1 regulates the dendrite MT polarity through directly gliding the plus-end-out MTs out of the dendrite using both the motor domain and the C-terminal MT-binding domain. ${ }^{68}$ Besides, UNC-116/Kinisin-1 controls MT length and minus-end spacing in a cell-autonomous manner. ${ }^{69}$

\section{Kinesin and intraflagellar transport (IFT)}

IFT is a special intracellular transport which happens in cilia and flagella. During the IFT, the cilia components move bidirectional along axonemal microtubules, which is essential for the ciliogenesis and proper morphology and functions of most eukaryotic cilia and flagella. Of the 302 neurons found in the adult C. elegans hermaphrodite, a substantial number (about 60) possess cilia at the ends of their dendritic processes. ${ }^{71}$ Several KLPs have been reported involving in IFT, such as OSM-3, KLP-6, KLP-11, KLP-20. ${ }^{32,49,71,72}$ IFT in C. elegans usually involves two IFT-particles, namely $\mathrm{A}$ and $\mathrm{B}$, which respectively binds with heterotrimeric kinesin-II (KLP-11/KLP-20) and homodimeric KLP-2/OSM-3. These two IFT-particles form stable complex by $C$. elegans homologs of human Bardet-Biedl Syndrome (BBS) proteins (BBS-7 and BBS-8). ${ }^{32,49,71}$ Although lots of studies have identified the components of IFT-particles, most of them are only important for forming the IFT particle for delivery specific cargos. The IFT cargos are still largely unclear. Future efforts may focus on identifying cargos for specific IFT-related functions.

\section{Kinesin and human diseases}

Some human KIF1A mutations are correlated with hereditary spastic paraplegia (HSP). Most HSP-causing KIF1A mutations are located within the conserved motor domain. Considering that those mutations are usually dominant negative or recessive, and motor domain of KIF1A provides energy for cargo delivery, it is believed that these motor domain mutations likely induce HSP by reducing KIF1A-mediated transportation. ${ }^{73-75}$ By introducing KIF1A mutant KIF1A(V8I)/UNC-104(V6I), which can enhance motor activities, into C. elegans, Chiba et al. observed increased anterograde axonal transport of SVPs and their abnormal accumulation at the axon tips, proposing gain-of-function of KIF1A as a novel pathogenic mechanism of humans HSP. ${ }^{76}$ Together all these findings, it is suggested that proper cellular function of MT-based motors is essential for neuronal homeostasis in humans. ${ }^{76}$

\section{Regulatory mechanisms to kinesins}

Regulating kinesin activity is important to ensure their proper functioning, and their mis-regulation often leads to severe human neurological disorders. ${ }^{77}$ The activity of UNC-104/KIF1A is regulated by its cargo proteins. For example, kinesin-binding protein (KBP) regulates unc-104/KIF1A activity by interacting with its motor domains to prevent its association with the MT cytoskeleton. Depletion of KBP results in the accumulation of KIF1A motors and SVs in the axonal growth cone, suggesting KBP as a kinesin inhibitor that modulates MT-based cargo motility. ${ }^{77}$ SAM-4, an ortholog of human BLOC-1-related complex (BORC) subunit 5 , positively regulates the processivity, not the velocity, of the synaptic vesicle (SV) transport by binding to unc-104/KIF1A. ${ }^{78}$ A recent study showed that the conserved ARF-like small GTPase ARL-8 is localized to SVPs and directly activates UNC-104/KIF1A. This activation process relies on BORC, by activating ARL- 8 via its guanine nucleotide exchange factor activity. Thus, BORC contributes to the axonal transport of SVPs through indirectly regulating the activity of UNC-104/KIF1A. ${ }^{79}$ In addition, UNC-104/KIF1A also under the regulation of SYD-2, an ortholog of human PPFIA1 (PTPRF interacting protein alpha 1), PPFIA2, PPFIA3. ${ }^{80}$ LIN-2, an ortholog of human CASK (calcium/ calmodulin dependent serine protein kinase), forms a functional complex with SYD-2, which positively affects the velocity of UNC-104/KIF1A-mediated axon transport. UNC-104/KIF1A motor motility and Synaptobrevin-1 (SNB-1) cargo transport are largely diminished in neurons of LIN-2 knockout worms, which cannot be compensated by overexpressing SYD-2, suggesting LIN-2 being the more prominent activator of UNC-104/KIF1A. ${ }^{81}$

The fate of kinesin motors after delivery of their cargoes has been postulated to involve degradation at the nerve terminal, recycling via retrograde motors, and/or recycling via diffusion. For example, fate of UNC-104/KIF1A after delivering the cargo is under the regulation of its cargo protein. UNC-104/KIF1A binds to $\mathrm{PI}(4,5) \mathrm{P}_{2}$ through its $\mathrm{PH}$ domain for transporting SVs from the cell body towards the synapse. Disrupt the binding specificity between UNC-104/KIF1A and PI(4,5) $\mathrm{P}_{2}$ causes UNC-104/KIF1A degradation via the ubiquitin pathway, and finally leads to locomotory defects and reduced motor levels in the mutants animals. ${ }^{82}$ These findings suggest a regulatory mechanism of UNC-104/KIF1A-mediated SV transportation, also imply the existence of certain recycling mechanism of UNC-104/KIF1A. In contrast, individual UNC-116/ kinesin-1 motors can be utilized repeatedly based on a recycling mechanism through free diffusion. The distribution and recycling of kinesin-1 motors fits a "loose bucket brigade" where individual motors shift between active transport and free diffusion within neuronal processes. ${ }^{83}$

\section{Summary}

Although it's been more than 30 years since kinesin was named, kinesin-mediated intracellular transport is still far away from fully understood. With the technology innovations, we now can push 
the research further. Most studies in the kinesin research society focused on knockout animals. ${ }^{6,9}$ Recent studies showed that genetic compensation can be induced by deleterious mutations but not gene knockdowns. ${ }^{84,85}$ A future direction of kinesin research would be focusing on cell-specific knockdown or inducible conditional knockout animals. It may give us unexpected understandings to kinesin functions.

\section{Financial support and sponsorship}

Nil.

\section{Conflicts of interest}

There are no conflicts of interest.

\section{REFERENCES}

1. Hirokawa N, Noda Y. Intracellular transport and kinesin superfamily proteins, KIFs: structure, function, and dynamics. Physiol Rev 2008; 88(3): 1089-118.

2. Hirokawa N, Bloom GS, Vallee RB. Cytoskeletal architecture and immunocytochemical localization of microtubule-associated proteins in regions of axons associated with rapid axonal transport: the beta,beta'-iminodipropionitrile-intoxicated axon as a model system. $J$ Cell Biol 1985; 101(1): 227-39.

3. Vale RD, Reese TS, Sheetz MP. Identification of a novel force-generating protein, kinesin, involved in microtubule-based motility. Cell 1985; 42(1): 39-50.

4. Nitta R, Kikkawa M, Okada Y, Hirokawa N. KIF1A alternately uses two loops to bind microtubules. Science 2004; 305(5684): 678-83.

5. Noda Y, Niwa S, Homma N, Fukuda H, Imajo-Ohmi S, Hirokawa N. Phosphatidylinositol 4-phosphate 5-kinase alpha (PIPKa) regulates neuronal microtubule depolymerase kinesin, KIF2A and suppresses elongation of axon branches. Proc. Natl. Acad. Sci. U.S.A. 2012; 109(5): 1725-30.

6. Zhou RY, Niwa S, Homma N, Takei Y, Hirokawa N. KIF26A Is an Unconventional Kinesin and Regulates GDNF-Ret Signaling in Enteric Neuronal Development. Cell 2009; 139(4): 802-13.

7. Ari C, Borysov SI, Wu J, Padmanabhan J, Potter H. Alzheimer amyloid beta inhibition of Eg5/kinesin 5 reduces neurotrophin and/or transmitter receptor function. Neurobiol Aging 2014; 35(8): 1839-49.

8. Morfini GA, You YM, Pollema SL, Kaminska A, Liu K, Yoshioka K, Bjorkblom B, Coffey ET, Bagnato C, Han D, Huang CF, Banker G, Pigino G, Brady ST. Pathogenic huntingtin inhibits fast axonal transport by activating JNK3 and phosphorylating kinesin. Nat Neurosci 2009; 12(7): 864-71.

9. Yang W, Tanaka Y, Bundo M, Hirokawa N. Antioxidant signaling involving the microtubule motor KIF12 is an intracellular target of nutrition excess in beta cells. Dev Cell 2014; 31(2): 202-14.

10. Mrug M, Zhou JL, Yang CZ, Aronow BJ, Cui XQ, Schoeb TR, Siegal GP, Yoder BK, Guay-Woodford LM. Genetic and Informatic Analyses Implicate Kif12 as a Candidate Gene within the Mpkd2 Locus That Modulates Renal Cystic Disease Severity in the Cys1(cpk) Mouse. Plos One 2015; 10(8): e0135678.

11. Rath O, Kozielski F. Kinesins and cancer. Nat Rev Cancer 2012; 12(8): 527-39.

12. Zhao C, Takita J, Tanaka Y, Setou M, Nakagawa T, Takeda S, Yang HW, Terada S, Nakata T, Takei Y, Saito M, Tsuji S, Hayashi Y, Hirokawa N. Charcot-Marie-Tooth disease type $2 \mathrm{~A}$ caused by mutation in a microtubule motor KIF1B beta. Cell 2001; 105(5): 587-97.
13. Xu F, Takahashi H, Tanaka Y, Ichinose S, Niwa S, Wicklund M, Hirokawa N. KIF1B $\beta$ mutations detected in hereditary neuropathy impair IGF1R transport and axon growth. J Cell Biol 2018; 217(10): 3480-96.

14. Liu H, Yang WX, Wu TH, Duan FY, Soucy E, Jin X, Zhang Y. Cholinergic Sensorimotor Integration Regulates Olfactory Steering. Neuron 2018; 97(2): 390-405.

15. Guo M, Wu TH, Song YX, Ge MH, Su CM, Niu WP, Li LL, Xu ZJ, Ge CL, Al-Mhanawi MTH, Wu SP, Wu ZX. Reciprocal inhibition between sensory ASH and ASI neurons modulates nociception and avoidance in Caenorhabditis elegans. Nat Commun 2015; 6: 5655.

16. Hao YS, Yang WX, Ren J, Hall Q, Zhang Y, Kaplan JM. Thioredoxin shapes the C. elegans sensory response to Pseudomonas produced nitric oxide. eLife 2018; 7: e36833.

17. Yu JY, Yang WX, Liu H, Hao YS, Zhang Y. An Aversive Response to Osmotic Upshift in Caenorhabditis elegans. Eneuro 2017; 4(2): ENEURO.0282-16.2017.

18. Heintz C, Doktor TK, Lanjuin A, Escoubas CC, Zhang Y, Weir HJ, Dutta S, Silva-Garcia CG, Bruun GH, Morantte I, Hoxhaj G, Manning BD, Andresen BS, Mair WB. Splicing factor 1 modulates dietary restriction and TORC1 pathway longevity in C. elegans (vol 541, pg 102, 2017). Nature 2017; 547(7664): 476-76.

19. Koreth J, Van Den Heuvel S. Cell-cycle control in Caenorhabditis elegans: how the worm moves from G1 to S. Oncogene 2005; 24(17) 2756-64.

20. Pintard L, Bowerman B. Mitotic Cell Division in Caenorhabditis elegans. Genetics 2019; 211(1): 35-73.

21. Ohno H, Kato S, Naito Y, Kunitomo H, Tomioka M, Iino Y. Role of synaptic phosphatidylinositol 3-kinase in a behavioral learning response in C. elegans. Science 2014; 345(6194): 313-17.

22. Hoerndli FJ, Maxfield DA, Brockie PJ, Mellem JE, Jensen E, Wang R, Madsen DM, Maricq AV. Kinesin-1 Regulates Synaptic Strength by Mediating the Delivery, Removal, and Redistribution of AMPA Receptors. Neuron 2013; 80(6): 1421-37.

23. Glater EE, Megeath LJ, Stowers RS, Schwarz TL. Axonal transport of mitochondria requires milton to recruit kinesin heavy chain and is light chain independent. J Cell Biol 2006; 173(4): 545-57.

24. Kimura T, Arimura N, Fukata Y, Watanabe H, Iwamatsu A, Kaibuchi K. Tubulin and CRMP-2 complex is transported via Kinesin-1. Journal of Neurochemistry 2005; 93(6): 1371-82.

25. Kanai Y, Dohmae N, Hirokawa N. Kinesin transports RNA: Isolation and characterization of an RNA-transporting granule. Neuron 2004; 43(4): 513-25.

26. Arimoto M, Koushika SP, Choudhary BC, Li C, Matsumoto K, Hisamoto N. The Caenorhabditis elegans JIP3 Protein UNC-16 Functions As an Adaptor to Link Kinesin-1 with Cytoplasmic Dynein. J Neurosci 2011; 31(6): 2216-24.

27. Takeda S, Yamazaki H, Seog DH, Kanai Y, Terada S, Hirokawa N. Kinesin superfamily protein 3 (KIF3) motor transports fodrin-associating vesicles important for neurite building. J Cell Biol 2000; 148(6): 1255-65.

28. Tanaka Y, Niwa S, Dong M, Farkhondeh A, Wang L, Zhou RY, Hirokawa N. The Molecular Motor KIF1A Transports the TrkA Neurotrophin Receptor and Is Essential for Sensory Neuron Survival and Function. Neuron 2016; 90(6): 1215-29.

29. Otsuka AJ, Jeyaprakash A, Garciaanoveros J, Lan ZT, Fisk G, Hartshorne T, Franco R, Born T. The C. elegans Unc-104 Gene Encodes a Putative Kinesin Heavy-Chain Like Protein. Neuron 1991; 6(1): 113-22.

30. Maeder CI, San-Miguel A, Wu EY, Lu H, Shen K. In vivo neuron-wide analysis of synaptic vesicle precursor trafficking. Traffic 2014; 15(3): 
273-91.

31. Shakir MA, Fukushige T, Yasuda H, Miwa J, Siddiqui SS. C. elegans Osm-3 Gene Mediating Osmotic Avoidance-Behavior Encodes a Kinesin-Like Protein. Neuroreport 1993; 4(7): 891-94.

32. Pan XY, Ou GS, Civelekoglu-Scholey G, Blacque OE, Endres NF, Tao L, Mogilner A, Leroux MR, Vale RD, Scholey JM. Mechanism of transport of IFT particles in C. elegans cilia by the concerted action of kinesin-II and OSM-3 motors. J Cell Biol 2006; 174(7): 1035-45.

33. Khan MLA, Gogonea CB, Siddiqui ZK, Ali MY, Kikuno R, Nishikawa $\mathrm{K}$, Siddiqui SS. Molecular cloning and expression of the Caenorhabditis elegans klp-3, an ortholog of C terminus motor kinesins Kar3 and ncd. Journal of Molecular Biology 1997; 270(5): 627-39.

34. Monteiro MI, Ahlawat S, Kowalski JR, Malkin E, Koushika SP, Juo P. The kinesin-3 family motor KLP-4 regulates anterograde trafficking of GLR-1 glutamate receptors in the ventral nerve cord of Caenorhabditis elegans. Mol Biol Cell 2012; 23(18): 3647-62.

35. Siddiqui SS. Metazoan motor models: Kinesin superfamily in C. elegans. Traffic 2002; 3(1): 20-28.

36. Peden EM, Barr MM. The KLP-6 kinesin is required for male mating behaviors and polycystin localization in Caenorhabditis elegans. Curr Biol 2005; 15(5): 394-404.

37. Tanaka K, Sugiura Y, Ichishita R, Mihara K, Oka T. KLP6: a newly identified kinesin that regulates the morphology and transport of mitochondria in neuronal cells. J Cell Sci 2011; 124(14): 2457-65.

38. Ghosh-Roy A, Goncharov A, Jin YS, Chisholm AD. Kinesin-13 and Tubulin Posttranslational Modifications Regulate Microtubule Growth in Axon Regeneration. Dev Cell 2012; 23(4): 716-28.

39. Raich WB, Moran AN, Rothman JH, Hardin J. Cytokinesis and midzone microtubule organization in Caenorhabditis elegans require the kinesin-like protein ZEN-4. Mol Biol Cell 1998; 9(8): 2037-49.

40. Lee KY, Green RA, Gutierrez E, Gomez-Cavazos JS, Kolotuev I, Wang SH, Desai A, Groisman A, Oegema K. CYK-4 functions independently of its centralspindlin partner ZEN-4 to cellularize oocytes in germline syncytia. eLife 2018; 7: e36919.

41. Khan MLA, Ali MY, Siddiqui ZK, Shakir MA, Ohnishi H, Nishikawa K, Siddiqui SS. C. elegans KLP-11/OSM-3/KAP-1: Orthologs of the sea urchin Kinesin-II, and mouse KIF3A/KIFB/KAP3 kinesin complexes. DNA Res 2000; 7(2): 121-25.

42. Powers J, Rose DJ, Saunders A, Dunkelbarger S, Strome S, Saxton WM. Loss of KLP-19 polar ejection force causes misorientation and missegregation of holocentric chromosomes. J Cell Biol 2004; 166(7): 991-1001.

43. Robin G, Debonis S, Dornier A, Cappello G, Ebel C, Wade RH, Thierry-Mieg D, Kozielski F. Essential kinesins: Characterization of Caenorhabditis elegans KLP-15. Biochemistry-Us 2005; 44(17): 6526-36.

44. Ali MY, Siddiqui ZK, Malik AB, Siddiqui SS. A novel C-terminal kinesin subfamily may be involved in chromosomal movement in Caenorhabditis is elegans. Febs Lett 2000; 470(1): 70-76.

45. Ali MY, Siddiqui SS. cDNA cloning and expression of a C-terminus motor kinesin-like protein KLP-17, involved in chromosomal movement in Caenorhabditis elegans. Biochem Bioph Res Co 2000; 267(2): 643-50.

46. Segbert C, Barkus R, Powers J, Strome S, Saxton WM, Bossinger O. KLP-18, a Klp2 kinesin, is required for assembly of acentrosomal meiotic spindles in Caenorhabditis elegans. Mol Biol Cell 2003; 14(11): 4458-69.

47. Wolff ID, Tran MV, Mullen TJ, Villeneuve AM, Wignall SM. Assembly of Caenorhabditis elegans acentrosomal spindles occurs without evident microtubule-organizing centers and requires microtubule sorting by KLP-18/kinesin-12 and MESP-1. Mol Biol Cell 2016; 27(20): 3122-31.

48. Pelisch F, Tammsalu T, Wang B, Jaffray EG, Gartner A, Hay RT. A SUMO-Dependent Protein Network Regulates Chromosome Congression during Oocyte Meiosis. Mol Cell 2017; 65(1): 66-77.

49. Yi PS, Li WJ, Dong MQ, Ou GS. Dynein-Driven Retrograde Intraflagellar Transport Is Triphasic in C. elegans Sensory Cilia. Curr Biol 2017; 27(10): 1448-61.

50. Patel N, Thierrymieg D, Mancillas JR. Cloning by Insertional Mutagenesis of a cDNA-encoding Caenorhabditis elegans Kinesin Heavy-Chain. P Natl Acad Sci USA 1993; 90(19): 9181-85.

51. Sakamoto R, Byrd DT, Brown HM, Hisamoto N, Matsumoto K, Jin Y. The Caenorhabditis elegans UNC-14 RUN domain protein binds to the kinesin-1 and UNC-16 complex and regulates synaptic vesicle localization. Mol Biol Cell 2005; 16(2): 483-96.

52. Yue Y, Sheng Y, Zhang HN, Yu Y, Huo L, Feng W, Xu T. The CC1-FHA dimer is essential for KIF1A-mediated axonal transport of synaptic vesicles in C. elegans. Biochem Bioph Res Co 2013; 435(3): 441-46.

53. Lipton DM, Maeder CI, Shen K. Rapid Assembly of Presynaptic Materials behind the Growth Cone in Dopaminergic Neurons Is Mediated by Precise Regulation of Axonal Transport. Cell Reports 2018; 24(10): 2709-22.

54. Li LB, Lei HY, Arey RN, Li PP, Liu JF, Murphy CT, Xu XZS, Shen K. The Neuronal Kinesin UNC-104/KIF1A Is a Key Regulator of Synaptic Aging and Insulin Signaling-Regulated Memory. Curr Biol 2016; 26(5): 605-15.

55. Stavoe AKH, Hill SE, Hall DH, Colon-Ramos DA. KIF1A/UNC-104 Transports ATG-9 to Regulate Neurodevelopment and Autophagy at Synapses. Dev Cell 2016; 38(2): 171-85.

56. Thapliyal S, Vasudevan A, Dong YM, Bai JH, Koushika SP, Babu K. The C-terminal of CASY-1/Calsyntenin regulates GABAergic synaptic transmission at the Caenorhabditis elegans neuromuscular junction. Plos Genet 2018; 14(3): e1007263.

57. Hoerndli FJ, Wang R, Mellem JE, Kallarackal A, Brockie PJ, Thacker C, Madsen DM, Maricq AV. Neuronal Activity and CaMKII Regulate Kinesin-Mediated Transport of Synaptic AMPARs. Neuron 2015; 86(2): 457-74.

58. Martin M, Iyadurai SJ, Gassman A, Gindhart JG, Hays TS, Saxton WM. Cytoplasmic dynein, the dynactin complex, and kinesin are interdependent and essential for fast axonal transport. Mol Biol Cell 1999; 10(11): 3717-28.

59. Park M, Watanabe S, Poon VVN, Ou CY, Jorgensen EM, Shen K. CYY-1/Cyclin Y and CDK-5 Differentially Regulate Synapse Elimination and Formation for Rewiring Neural Circuits. Neuron 2011; 70(4): 742-57.

60. Meng LF, Mulcahy B, Cook SJ, Neubauer M, Wan AR, Jin YS, Yan D. The Cell Death Pathway Regulates Synapse Elimination through Cleavage of Gelsolin in Caenorhabditis elegans Neurons. Cell Reports 2015; 11(11): 1737-48.

61. Kurup N, Yan D, Goncharov A, Jin YS. Dynamic Microtubules Drive Circuit Rewiring in the Absence of Neurite Remodeling. Curr Biol 2015; 25(12): 1594-605.

62. Barsi-Rhyne BJ, Miller KM, Vargas CT, Thomas AB, Park J, Bremer M, Jarecki JL, Vanhoven MK. Kinesin-1 Acts with Netrin and DCC to Maintain Sensory Neuron Position in Caenorhabditis elegans. Genetics 2013; 194(1): 175-87.

63. Moores CA, Milligan RA. Lucky 13 - microtubule depolymerisation by kinesin-13 motors. J Cell Sci 2006; 119(19): 3905-13.

64. Han X, Adames K, Sykes EME, Srayko M. The KLP-7 Residue S546 Is a Putative Aurora Kinase Site Required for Microtubule Regulation at 
the Centrosome in C. elegans. Plos One 2015; 10(7): e0132593.

65. Gigant E, Stefanutti M, Laband K, Gluszek-Kustusz A, Edwards F, Lacroix B, Maton G, Canman JC, Welburn JPI, Dumont J. Inhibition of ectopic microtubule assembly by the kinesin-13 KLP-7 prevents chromosome segregation and cytokinesis defects in oocytes. Development 2017; 144(9): 1674-86.

66. Rawson RL, Yam L, Weimer RM, Bend EG, Hartwieg E, Horvitz HR, Clark SG, Jorgensen EM. Axons Degenerate in the Absence of Mitochondria in C. elegans. Curr Biol 2014; 24(7): 760-65.

67. Hall DH, Hedgecock EM. Kinesin-Related Gene Unc-104 Is Required for Axonal-Transport of Synaptic Vesicles in C. elegans. Cell 1991; 65(5): 837-47.

68. Yan J, Chao DL, Toba S, Koyasako K, Yasunaga T, Hirotsune S, Shen K. Kinesin-1 regulates dendrite microtubule polarity in Caenorhabditis elegans. eLife 2013; 2: e00133.

69. Yogev S, Cooper R, Fetter R, Horowitz M, Shen K. Microtubule Organization Determines Axonal Transport Dynamics. Neuron 2016; 92(2): 449-60.

70. Harterink M, Edwards SL, De Haan B, Yau KW, Van Den Heuvel S, Kapitein LC, Miller KG, Hoogenraad CC. Local microtubule organization promotes cargo transport in C. elegans dendrites. J Cell Sci 2018; 131(20): doi: 10.1242/jcs.223107.

71. Inglis PN, Ou G, Leroux MR, Scholey JM. The sensory cilia of Caenorhabditis elegans. WormBook 2007: 1-22.

72. Morsci NS, Barr MM. Kinesin-3 KLP-6 regulates intraflagellar transport in male-specific cilia of Caenorhabditis elegans. Curr Biol 2011; 21(14): 1239-44.

73. Klebe S, Lossos A, Azzedine H, Mundwiller E, Sheffer R, Gaussen M, Marelli C, Nawara M, Carpentier W, Meyer V, Rastetter A, Martin E, Bouteiller D, Orlando L, Gyapay G, El-Hachimi KH, Zimmerman B, Gamliel M, Misk A, Lerer I, Brice A, Durr A, Stevanin G. KIF1A missense mutations in SPG30, an autosomal recessive spastic paraplegia: distinct phenotypes according to the nature of the mutations. Eur J Hum Genet 2012; 20(6): 645-49.

74. Nieh SE, Madou MRZ, Sirajuddin M, Fregeau B, Mcknight D, Lexa K, Strober J, Spaeth C, Hallinan BE, Smaoui N, Pappas JG, Burrow TA, Mcdonald MT, Latibashvili M, Leshinsky-Silver E, Lev D, Blumkin L, Vale RD, Barkovich AJ, Sherr EH. De novo mutations in KIF1A cause progressive encephalopathy and brain atrophy. Ann Clin Transl Neur $2015 ; 2(6): 623-35$.
75. Boutry M, Morais S, Stevanin G. Update on the Genetics of Spastic Paraplegias. Curr Neurol Neurosci 2019; 19(4).

76. Chiba K, Min C, Arai S, Hashimoto K, Mckenney RJ, Niwa S. Disease-associated mutations hyperactivate KIF1A motility and anterograde axonal transport of synaptic vesicle precursors. bioRxiv 2019: DOI:10.1101/597906.

77. Kevenaar JT, Bianchi S, Van Spronsen M, Olieric N, Lipka J, Frias CP, Mikhaylova M, Harterink M, Keijzer N, Wulf PS, Hilbert M, Kapitein LC, De Graaff E, Ahkmanova A, Steinmetz MO, Hoogenraad CC. Kinesin-Binding Protein Controls Microtubule Dynamics and Cargo Trafficking by Regulating Kinesin Motor Activity. Curr Biol 2016; 26(7): 849-61.

78. Zheng Q, Ahlawat S, Schaefer A, Mahoney T, Koushika SP, Nonet ML. The Vesicle Protein SAM-4 Regulates the Processivity of Synaptic Vesicle Transport. Plos Genet 2014; 10(10): e1004644.

79. Niwa S, Tao L, Lu SY, Liew GM, Feng W, Nachury MV, Shen K. BORC Regulates the Axonal Transport of Synaptic Vesicle Precursors by Activating ARL-8. Curr Biol 2017; 27(17): 2569-78.

80. Wagner OI, Esposito A, Kohler B, Chen CW, Shen CP, Wu GH, Butkevich E, Mandalapu S, Wenzel D, Wouters FS, Klopfenstein DR. Synaptic scaffolding protein SYD-2 clusters and activates kinesin-3 UNC-104 in C. elegans. P Natl Acad Sci USA 2009; 106(46): 19605-10.

81. Wu GH, Shanmugam MM, Bhan P, Huang YH, Wagner OI. Identification and Characterization of LIN-2(CASK) as a Regulator of Kinesin-3 UNC-104(KIF1A) Motility and Clustering in Neurons. Traffic 2016; 17(8): 891-907.

82. Kumar J, Choudhary BC, Metpally R, Zheng Q, Nonet ML, Ramanathan S, Klopfenstein DR, Koushika SP. The Caenorhabditis elegans Kinesin-3 Motor UNC-104/KIF1A Is Degraded upon Loss of Specific Binding to Cargo. Plos Genet 2010; 6(11): e1001200.

83. Blasius TL, Reed N, Slepchenko BM, Verhey KJ. Recycling of Kinesin-1 Motors by Diffusion after Transport. Plos One 2013; 8(9): e76081.

84. Rossi A, Kontarakis Z, Gerri C, Nolte H, Holper S, Kruger M, Stainier DYR. Genetic compensation induced by deleterious mutations but not gene knockdowns. Nature 2015; 524(7564): 230-33.

85. Ma Z, Zhu P, Shi H, Guo L, Zhang Q, Chen Y, Chen S, Zhang Z, Peng J, Chen J. PTC-bearing mRNA elicits a genetic compensation response via Upf3a and COMPASS components. Nature 2019; 568(7751): 259-63. 